\title{
Critérios para a avaliação da oralidade no ensino de lingua portuguesa
}

Criteria for orality assessment on Portuguese language teaching

Flávia Santana Araújo

Universidade Federal de Pernambuco - UFPE

Lívia Suassuna

Universidade Federal de Pernambuco - UFPE

DOI: https://doi.org/10.5902/2176148538796

\begin{abstract}
Resumo: Em se tratando da avaliação da aprendizagem de modo geral, é necessário que o professor tenha clareza dos objetos de ensino e das expectativas de aprendizagem, para que estes se articulem de forma coerente aos procedimentos metodológicos adotados. Isso também se aplica ao ensino da modalidade falada da língua portuguesa. Nesse sentido, o objetivo deste ensaio é discutir o ensino da oralidade e sua avaliação, bem como propor critérios avaliativos para o acompanhamento da aprendizagem da língua falada. Para embasar a discussão, são trazidos alguns estudos, tais como Schneuwly (2004) e Melo e Cavalcante (2007).
\end{abstract}

Palavras-chave: Critérios. Avaliação. Oralidade.

Abstract: In terms of the evaluation of learning in general, it is necessary that the teacher has clarity of teaching objects and learning expectations so that they are articulated in a manner consistent with the methodological procedures adopted. This also applies to teaching the spoken modality of the Portuguese language. In this sense, the objective of this essay is to discuss the teaching of orality and its evaluation, as well as to propose evaluation criteria for the accompaniment of the learning of the spoken language. To support the discussion, some studies are presented, such as Schneuwly (2004) and Melo and Cavalcante (2007).

Keywords: Criteria. Assessment. Orality. 


\section{Introdução}

Em se tratando de um ensino de língua baseado num enfoque sociointeracionista, é necessário que o professor tenha clareza sobre os objetivos de ensino, para que suas escolhas metodológicas sejam coerentes com os mesmos, uma vez que eles guiam o fazer em sala de aula. Logicamente, isso também se aplica ao ensino da língua falada. $O$ objetivo agora não

Flávia Santana

Araújo

Lívia

Suassuna

98 é ensinar a língua por meio da abordagem de suas regras gramaticais, como antigamente se costumava fazer, mas sim ensinar os meios mais adequados para sua utilização, levando em consideração os mais variados contextos sociais: "a língua tem um vocabulário, uma gramática e certas normas que devem ser observadas na produção dos gêneros textuais de acordo com as normas sociais e necessidades cognitivas adequadas à situação concreta e aos interlocutores" (MARCUSCHI; DIONÍSIO, 2007, p. 16).

Milanez (1993) ressalta que o trabalho com a oralidade deve ser realizado desde os primeiros anos da educação escolar, com vistas a aperfeiçoar a competência comunicativa do aluno nos mais diversos contextos sociais em que possa vir a interagir. Para a autora, trata-se de tornar consciente o que é intuitivo sobre a língua falada, através de um ensino sistemático cujo foco recaia sobre os atos de linguagem. "Assim, é importante que o aluno perceba que a diversidade de produções orais existe, principalmente, em função da situação em que o discurso se realiza" (MILANEZ, 1993, p. 25).

Em pesquisa feita com professores de português das séries finais do ensino fundamental de diversos municípios do estado do Piauí, Ávila, Nascimento e Gois (2012, p. 47) observaram que "os objetivos do ensino da oralidade: (a) muitas vezes não se fazem presentes; (b) quando aparecem, são essencialmente voltados para a aprendizagem da escrita; ou (c) revelam uma capacidade reducionista de um trabalho efetivo com gêneros textuais".

Já no ensino médio o trabalho com a oralidade geralmente acontece, porém de forma limitada, já que no contexto brasileiro, a emergência do Estado avaliador, com seus exames focados na aprendizagem da escrita, acaba por levar muitos professores a colocar o trabalho com a língua falada em segundo plano. Araújo (2014), em pesquisa com professores da rede estadual de Pernambuco em que analisou as práticas de avaliação da oralidade, percebeu que o trabalho com a língua falada acontecia sistematicamente por meio de gêneros orais. No entanto, algumas práticas avaliativas eram realizadas de maneira pontual, desconsiderando-se aspectos essenciais no desenvolvimento da língua falada dos alunos. 
Considerando-se essas e outras discussões, o objetivo deste ensaio é discutir o ensino da oralidade e sua avaliação, bem como propor critérios avaliativos para o acompanhamento da aprendizagem da língua falada. Tais critérios são fruto de reflexões provocadas pelas leituras de diversos autores, como também da análise de dados de pesquisas científicas. Ressaltamos que os critérios ora apresentados não devem ser vistos como estanques, dada a dinâmica própria do ensino de língua.

\section{Como trabalhar a oralidade nas aulas de língua materna?}

O ensino de língua falada se apoia em concepções diversas, que vão desde a leitura em voz alta até um trabalho interativo com gêneros textuais orais. Schneuwly (2004) fez uma pesquisa com professores-estudantes de Ciências da Educação sobre concepções de oralidade na Suíça, na qual ele perguntou aos professores "O que é o oral para você?". O pesquisador percebeu que as respostas recebidas apontavam para concepções usuais de ensino de oralidade, as quais foram divididas em três grupos:

1) oral como materialidade: ensino focado exclusivamente na exploração da fala;

2) oral como espontaneidade: o estudante é levado a expressar-se espontaneamente por meio da fala;

3) oral como norma: o objetivo é levar o estudante a falar corretamente, dando ênfase a aspectos normativos da língua.

Tais concepções usuais de oralidade acarretam diversos problemas no seu tratamento didático. Ao entender o oral apenas como materialidade, o docente preocupa-se mais com os aspectos prosódicos da fala, desprezando outros aspectos (cinésicos, por exemplo). Já quando se concebe o oral como espontaneidade, desconsidera-se que o próprio contexto regula as interações ocorridas por meio da língua, ou seja, a fala não é de todo espontânea. Por fim, ao se entendermos o oral como norma, deixaremos de lado as inúmeras variedades linguísticas de que se lança mão nos usos sociais da língua.

Esses e outros problemas surgem porque o foco do ensino de oralidade recai sobre um aspecto específico, seja ele voltado ao desenvolvimento de habilidades articulatórias, conversacionais ou linguísticas. Ora, se a fala é um objeto complexo e multifacetado, transcendendo, inclusive, a sua própria materialização fonético-fonológica, visto que 
Flávia Santana

Araújo

Lívia

Suassuna

100

se utiliza de elementos corporais e outros, eleger apenas um de seus atributos como foco para o ensino de língua falada seria descaracterizar a sua natureza interacional (supondo-se aqui uma concepção linguística apoiada na interação verbal), desvinculando-o das práticas comunicativas realizadas em sociedade por meio da língua.

Em oposição às concepções usuais, Schneuwly (2004) apresenta uma concepção do desenvolvimento (ou sociointeracionista), tendo como princípios: a) levar o estudante a conhecer e dominar bem a sua língua materna em contextos sociais diversos; b) desenvolver nos aprendizes uma relação consciente e voluntária com seu próprio comportamento linguístico; c) construir representações de atividades de fala em situações complexas. Assim, ele entende que essa concepção de ensino de oralidade só pode ser concretizada por meio do trabalho com gêneros textuais orais. Após discutir sobre a concepção para o ensino do oral apoiada numa perspectiva sociointeracionista, Schneuwly (2004, p. 117) defende:

\footnotetext{
Parece, portanto, mais propício não entrar no oral em geral, mas em gêneros orais, e trabalhar suas especificidades. Trabalhar os orais pode dar acesso ao aluno a uma gama de atividades de linguagem e, assim, desenvolver capacidades de linguagem diversas; abrem-se, igualmente, caminhos diversificados que podem convir aos alunos de maneiras muito diferenciadas, segundo suas personalidades.
}

Dessa forma, o ensino da língua falada deve levar a desenvolver práticas de linguagem às quais normalmente o estudante não teria acesso em seu cotidiano. Em se tratando do ensino médio, e considerando-se os diferentes campos de atuação social, esse trabalho com a língua falada precisa desenvolver a autonomia de uso da linguagem em esferas comunicativas variadas. Para Dolz, Schneuwly e Haller (2004, p. 147), o ensino da oralidade deve privilegiar os gêneros orais formais públicos: "Os gêneros formais públicos constituem as formas de linguagem que apresentam restrições impostas do exterior e implicam, paradoxalmente, um controle mais consciente e voluntário do próprio comportamento para dominá-las.".

Se compararmos a modalidade escrita da língua à falada, veremos que um aspecto é essencial no ensino desta última: a interação instantânea. Faz-se necessário, portanto, simular situações em sala de 
aula que sejam bem próximas da realidade e nas quais o estudante seja levado a dominar os recursos implicados na interação por meio da fala. A esse princípio metodológico de trabalho com os gêneros textuais que aproxima o estudante das situações cotidianas em que a linguagem é utilizada Schneuwly (2004) dá o nome de ficcionalização. Segundo ele:

A particularidade do oral em relação à escrita reside no fato de que essa ficcionalização deve se articular com uma representação do aqui e agora, gerenciada simultaneamente, graças aos meios de linguagem que são o gesto, a mímica, a corporalidade, a prosódia. Palavra - implicação material e corporal na situação de linguagem - e ficcionalização - a necessidade de construir, ao mesmo tempo, uma representação da situação abstrata - constituem, portanto, os dois vetores a partir dos quais se constroem as novas capacidades de linguagem no que chamamos de o oral (SCHNEUWLY, 2004, p. 123).
Critérios para a avaliação da oralidade no ensino de língua portuguesa

Sabemos que, quando um gênero entra na escola, sofre modificações, visto que ele é, simultaneamente, "gênero a aprender, embora permaneça gênero para comunicar" (SCHNEUWLY; DOLZ, 2004, p. 69). $O$ docente deve estar atento, portanto, às adaptações que precisará realizar nessa aprendizagem do gênero, para não incorrer no equívoco de retirar desse gênero características essenciais à sua compreensão. Em outras palavras, trata-se não apenas de alcançar o domínio de um gênero em específico, mas também, e principalmente, de desenvolver habilidades que ultrapassem o modelo relativamente estável desse gênero.

\section{Como avaliar a oralidade nas aulas de língua portuguesa?}

Tendo em vista, portanto, as mudanças que todo gênero textual sofre ao adentrar a sala de aula, a elaboração de um determinado modelo didático de gênero pode orientar-se pelos seguintes princípios: 1) legitimidade, ou "quais saberes teóricos ensinar?"; 2) pertinência, ou "quais os objetivos de ensino?"; 3) solidarização, ou "os saberes estão alinhados aos objetivos?". Um modelo didático de gênero deveria atender, dessa forma, tanto aos objetivos práticos do ensino de língua materna, quanto às características do gênero textual em questão, estando ambas as dimensões interligadas. A hipótese levantada pelos autores é a seguinte: 
Flávia Santana

Araújo

Lívia

Suassuna

102

“[...] quanto mais precisa a definição das dimensões ensináveis de um gênero, mais ela facilitará a apropriação deste como instrumento e possibilitará o desenvolvimento de capacidades de linguagem diversas que a ele estão associadas" (SCHNEUWLY; DOLZ, p. 76, 2004).

Para Dolz, Noverraz e Schneuwly (2004, p. 82): “Uma sequência didática é um conjunto de atividades escolares organizadas, de maneira sistemática, em torno de um gênero textual oral ou escrito.". o procedimento de uma sequência didática inicia-se com a apresentação da situação a ser trabalhada: o professor apresenta um problema de comunicação e explora os conteúdos subjacentes a esse problema. Após essa etapa, dá-se a produção inicial, na qual o aluno produz o texto requerido mobilizando os conhecimentos de que dispõe. Depois dessa produção vêm os módulos, que compreendem blocos de atividades de sistematização dos conhecimentos linguísticos que o aluno revelou não dominar na primeira produção. Essa sistematização levará à produção final, em que o aluno consolidará os conhecimentos adquiridos ao longo da sequência, reelaborando a produção inicial.

Cremos, portanto, que, para a realização de práticas de oralidade em aulas de língua materna, um acompanhamento contínuo é indispensável, devido ao caráter imediatista da fala, que configura as produções textuais orais produzidas em sala de aula como situações comunicativas únicas. Assim, a construção modular de uma sequência didática favorece uma avaliação formativa, porque requer do professor um acompanhamento contínuo e crítico da aprendizagem de seus alunos. Ao contrário da visão tradicional de avaliação, que considera a mensuração de habilidades cognitivas apenas no final de cada etapa da aprendizagem, a avaliação formativa pressupõe o acompanhamento de todo o processo de construção de conhecimento.

É importante que a avaliação aconteça desde a produção inicial, para que o docente possa planejar melhor sua prática pedagógica a partir das necessidades de sua turma, e até individualizar sua intervenção pedagógica, caso necessário. “A análise das produções orais ou escritas dos alunos, guiadas por critérios bem definidos, permite avaliar de maneira bastante precisa em que ponto está a classe e quais são as dificuldades encontradas pelos alunos" (DOLZ; NOVERRAZ; SCHNEUWLY, 2004, p. 87).

Consoante essa perspectiva, o professor deverá atuar como mediador da aprendizagem no ensino de língua. Lima e Beserra (2012, p. 70) enfatizam a importância das mediações do professor no processo 
de aprendizagem da oralidade: "Na realização das atividades orais, o professor desempenha o importantíssimo papel de mediar a produção, ajudando seus alunos a encontrar estratégias que permitam o desenvolvimento das habilidades requeridas".

Milanez (1992), ao tratar do papel do professor no processo de ensino da linguagem oral, denuncia em suas considerações finais o descompasso entre os estudos científicos e o trabalho pedagógico em sala de aula, fruto de uma formação sabidamente deficiente no tocante ao trabalho sistemático com a fala. Além disso, muitos docentes ainda mantêm uma postura autoritária, resultante de práticas tradicionais de abordagem da língua, dificultando uma abordagem interacionista. Em outro trecho de sua pesquisa ela também coloca o professor como peça fundamental nesse processo:

Critérios para a avaliação da oralidade no ensino de língua portuguesa

[...] cabe ao professor estar preparado para orientar os alunos em suas produções orais, uma vez que estas exigem treinamento e avaliação totalmente diferentes daqueles próprios das produções escritas, pelo fato de os interlocutores estarem em presença um(s) do(s) outro(s) e de o processo de comunicação envolver [...] reações, relações e influências recíprocas (MILANEZ, 1992, p. 135).

Sobre a questão do falar corretamente, abordagem centrada na exploração de regras da gramática normativa, a mesma autora enfatiza que não se trata de uma questão de respeito à norma culta exclusivamente, mas sim de consciência dos usos mais adequados a cada situação: “Numa abordagem interacional da língua, 'saber falar' não é só saber expressar o pensamento nem só conseguir ser entendido, mas atingir o objetivo dentro de determinada situação comunicativa" (MILANEZ, 1992, p. 170, grifo original).

A mesma autora ressalta ainda que os critérios de avaliação dos textos orais devem ser diversificados, contemplando diversos níveis de análise que ultrapassam a correção gramatical e incluindo, dessa forma, o aspecto comunicativo-interacional. Conforme a visão da autora, se se levam em conta apenas os aspectos gramaticais “[...] pode-se cair no erro de desconsiderar, no texto do aluno, aspectos qualitativamente positivos a nível discursivo que são atualmente reconhecidos como mais relevantes no processo interlocutivo do que a correção gramatical" (MILANEZ, 1993, p. 208). 


\section{Flávia Santana}

Araújo

Lívia

Suassuna

104

Entendemos que a essa visão sociointeracionista deva acrescentar-se o foco nas estratégias organizacionais de cada gênero, uma vez que elas são definidoras do processo de interação no qual a produção textual se enquadra. Dado o caráter de construção de conhecimento da sequência didática, que pressupõe uma progressão em espiral do conhecimento, a ênfase da avaliação deverá recair sobre o processo de aprendizagem dos estudantes. Para guiar essa avaliação, pode-se atentar para as camadas do folhado textual de que fala Bronckart (1999):

1) infraestrutura geral do texto: nesta camada verificam-se os tipos de discurso e suas articulações, e a organização do conteúdo temático, através da qual, enfim, pode-se caracterizar o gênero ao qual pertence o texto;

2) mecanismos de textualização: verifica-se a progressão do conteúdo temático, tendo em conta as grandes organizações hierárquicas, lógicas ou temporais de um texto, dentro de três conjuntos: conexão, coesão nominal e coesão verbal.

3) mecanismos enunciativos: esta camada contribui para a coerência pragmática do texto, apontando posicionamentos enunciativos, articulação das vozes presentes e avaliações do conteúdo temático.

\section{Quais critérios utilizar para a avaliação da aprendizagem da oralidade?}

Ao tratarem sobre o que avaliar no oral, Melo e Cavalcante (2007) fazem uma adaptação de um quadro proposto por Luiz Antônio Marcuschi durante o curso "Fala e escrita: características e usos" e de outro quadro apresentado por Dolz, Schneuwly e Haller (2004, p. 134). As autoras enumeram três agrupamentos de critérios a serem considerados na avaliação dos gêneros orais: extralinguísticos (relacionados ao contexto comunicativo); paralinguísticos (referem-se à maneira de produzir a fala); linguísticos (compreendem as estratégias de interação verbal e o uso adequado da língua no contexto comunicativo).

Aos critérios paralinguísticos, as autoras acrescentam os aspectos cinésicos, os quais englobam os movimentos corporais que acompanham a fala. Quando tratam desse agrupamento em específico, as pesquisadoras retomam a relação existente entre palavra e corpo. Para elas: "A postura corporal também se coloca a serviço da comunicação oral. Esta não se esgota somente na utilização de meios linguísticos ou prosódicos; utiliza também signos de sistemas semióticos não linguísti- 
cos, como a gestualidade." (MELO; CAVALCANTE, 2007, p. 86). Frisa-se ainda que, em muitos casos, a comunicação verbal realizada por meio da fala pode ser até mesmo substituída por alguns recursos cinésicos.

Mais recentemente, a teoria da multimodalidade tem se voltado essa multiplicidade de modalidades presentes nos textos (inclusive os orais), a partir de estudos da semiótica. De acordo com Kress e Van Leeuwen (2001 apud MELO; MARCUSCHI; CAVALCANTE, p. 2012, p. 99): “[...] o texto multimodal é aquele cujo significado se realiza por mais de um código semiótico (signos linguísticos, signos sonoros, signos imagéticos)." Nesse sentido, tendo como ponto de partida os estudos já citados e outros, além de nossas vivências enquanto docentes, propomos quatro agrupamentos de critérios para o trabalho com gêneros orais em sala de aula: discursivos, textuais, acústicos e cinésicos.

Critérios para a avaliação da oralidade no ensino de língua portuguesa

O grupo dos aspectos discursivos compreende aqueles relacionados às representações da situação comunicativa. Essas representações estão diretamente conectadas com os gêneros textuais, uma vez que sua regulação acontece a partir do meio social. Tais aspectos ultrapassariam o texto falado em si, auxiliando o interlocutor a escolher os melhores recursos para cada situação comunicativa. Abaixo descrevemos alguns desses aspectos:

\section{Quadro 1 - Agrupamento de aspectos discursivos dos gêneros orais}

\begin{tabular}{|l|l|}
\hline ASPECTO DISCURSIVO & DESCRIÇÃo \\
\hline Publicidade & $\begin{array}{l}\text { Quantidade de participantes envolvidos na situação } \\
\text { comunicativa, tornando-a mais ou menos pública. }\end{array}$ \\
\hline $\begin{array}{l}\text { Intimidade entre } \\
\text { os interlocutores }\end{array}$ & $\begin{array}{l}\text { Conhecimentos comuns/partilhados entre os interlocu- } \\
\text { tores, denotando mais ou menos intimidade. }\end{array}$ \\
\hline Participação emocional & $\begin{array}{l}\text { Maior ou menor grau de envolvimento na situação (emo- } \\
\text { cionalidade, expressividade, afetividade). }\end{array}$ \\
\hline Posição dos interlocutores & $\begin{array}{l}\text { Comunicação face a face ou entre pessoas que estão } \\
\text { geograficamente distantes. }\end{array}$ \\
\hline Organização de turnos & $\begin{array}{l}\text { Maior ou menor possibilidade de atuação do interlocutor } \\
\text { no evento comunicativo. }\end{array}$ \\
\hline Espontaneidade & Planejamento prévio (ou não) da comunicação. \\
\hline Formalidade do registro & $\begin{array}{l}\text { Reconhecimento do nível de formalidade exigido pela } \\
\text { situação comunicativa. }\end{array}$ \\
\hline $\begin{array}{l}\text { Reconhecimento do } \\
\text { contexto cultural }\end{array}$ & $\begin{array}{l}\text { Adaptação dos recursos linguísticos a situaçães vivencia- } \\
\text { das em espaços culturais diversificados. }\end{array}$ \\
\hline Estratégias de polidez & $\begin{array}{l}\text { Atos de fala com conotação positiva (elogiar, agrade- } \\
\text { cer, aceitar...) ou negativa (discordar, recusar, ofender, } \\
\text { xingar...). }\end{array}$ \\
\hline
\end{tabular}

Fonte: As autoras. 
Flávia Santana

Araújo

Lívia

Suassuna

106

Os aspectos textuais estariam relacionados a questões de construção de sentidos no texto, envolvendo também questões de ordem gramatical. Questões ligadas à composição textual, como coesão, coerência e unidade temática, estariam enumeradas nesse grupo, sugerindo uma compreensão do texto falado que não estaria presa ao falar corretamente (de acordo com a norma culta), mas incorporaria a noção de falar adequadamente. Para tanto, propomos o seguinte quadro:

\section{Quadro 2 - Agrupamento de aspectos textuais dos gêneros orais}

\begin{tabular}{|l|l|}
\hline ASPECTO TEXTUAL & DESCRIÇÃo \\
\hline $\begin{array}{l}\text { Marcadores } \\
\text { conversacionais }\end{array}$ & $\begin{array}{l}\text { Unidades típicas da fala que funcionam como articulado- } \\
\text { ras da conversação. }\end{array}$ \\
\hline Repetições & Duplicação de algum elemento que veio antes. \\
\hline Paráfrases & Reformulação de algo que veio antes. \\
\hline Correções & $\begin{array}{l}\text { Substituição de algum elemento que é retirado do enun- } \\
\text { ciado. }\end{array}$ \\
\hline Hesitações & $\begin{array}{l}\text { Expressões indicadoras de insegurança por parte do } \\
\text { falante. }\end{array}$ \\
\hline Digressões & $\begin{array}{l}\text { Suspensão temporária de um tópico retomado adiante; } \\
\text { apontam para algo externo ao que se acha em andamento. }\end{array}$ \\
\hline Expressões formulaicas & $\begin{array}{l}\text { Idiomatismos, provérbios, lugares-comuns, expressões } \\
\text { feitas, truísmos, rotinas, entre outros. }\end{array}$ \\
\hline Uso de modalizadores & $\begin{array}{l}\text { Termos ou expressões que apontam um posicionamento } \\
\text { do enunciador diante do texto. }\end{array}$ \\
\hline Fixação temática & Tema fixado (ou não) com antecedência \\
\hline
\end{tabular}

Fonte: As autoras.

O grupo dos aspectos acústicos englobaria as propriedades físicas da emissão de sons. Abarca, portanto, as características relacionadas à materialização do texto oral ocorrida por meio da fala. Algumas ciências linguísticas, como a fonética, a prosódia e a ortoépia, estudam esses fenômenos de produção da língua falada de forma mais detalhada. A fim de sugerir alguns aspectos a serem trabalhados pelos docentes, apresentamos o quadro abaixo: 


\section{Quadro 3 - Agrupamento de aspectos acústicos dos gêneros orais}

\begin{tabular}{|l|l|}
\hline ASPECTO ACÚSTICO & DESCRIÇÃo \\
\hline Qualidade vocal & Refere-se à qualidade da emissão (rouca, nasalizada...) \\
\hline Intensidade & Volume da voz em decibéis (alta, baixa...) \\
\hline Altura & Frequência da onda vocal em hertz (aguda, grave...) \\
\hline Elocução & Maneira de produzir a fala (lenta, rápida...) \\
\hline Pausas & Respirações durante a emissão (curtas, longas...) \\
\hline Interrupções & $\begin{array}{l}\text { Emissão de ruído distinto de enunciados verbais (riso, } \\
\text { choro, soluço, suspiro...) }\end{array}$ \\
\hline Entoação & $\begin{array}{l}\text { Variação de altura de fala que pode ocorrer em determi- } \\
\text { nada palavra ou oração }\end{array}$ \\
\hline Dicção & Pronúncia correta das palavras \\
\hline
\end{tabular}

Critérios para a avaliação da oralidade no ensino de língua portuguesa

Por fim, os aspectos cinésicos compreenderiam os recursos de linguagem corporal que dariam suporte à fala. Acreditamos que tais recursos, apesar de serem vistos como suporte para o oral, estão intimamente relacionados com a modalidade falada da língua. Assim, é de suma importância que o docente, ao trabalhar com gêneros orais, dedique parte do tempo desse trabalho à exploração de aspectos como os elencados a seguir:

Quadro 4 - Agrupamento de aspectos cinésicos dos gêneros orais

\begin{tabular}{|l|l|}
\hline ASPECTO CINÉSICO & DESCRIÇÃo \\
\hline Postura & Disposição do corpo em relação a outros interlocutores \\
\hline Gestos & $\begin{array}{l}\text { Movimentações feitas pelas articulações (principalmente } \\
\text { mãos e cabeça) }\end{array}$ \\
\hline Expressão facial & Mímicas faciais que acompanham a fala \\
\hline Olhares & Movimentação dos olhos durante a elocução \\
\hline Movimentação & $\begin{array}{l}\text { Deslocamento dos interlocutores no espaço comunica- } \\
\text { tivo }\end{array}$ \\
\hline
\end{tabular}

Fonte: As autoras.

Tais critérios, como já sinalizamos, não são estanques e certamente esses agrupamentos podem ser ampliados. O que importa destacar é a necessidade de que tanto o professor quanto os alunos tenham clareza dos critérios avaliativos da oralidade, para que haja uma coerência entre ensino e avaliação da aprendizagem. 

Flávia Santana
Araújo
Lívia
Suassuna da preocupação do professor de língua que adota uma perspectiva de ensino sociointeracionista baseada em gêneros textuais. Tal pers- pectiva, aliada a uma avaliação contínua da aprendizagem e guiada por critérios avaliativos previamente definidos, pode contribuir de maneira significativa para o desenvolvimento da língua falada dos aprendizes.

108

\section{Considerações finais}

Ao final da discussão aqui levantada, defendemos que fala é uma modalidade de uso da língua a serviço das práticas sociais de linguagem. Portanto, é importante identificar as aproximações e os distanciamentos entre fala e escrita, mas também, e principalmente, compreender que o tratamento da oralidade em sala de aula deve ser objeto

\section{REFERÊNCIAS}

ARAÚJO, Flávia Barbosa de Santana. A avaliação da oralidade em aulas de língua portuguesa do Ensino Médio. 138f. Dissertação (Mestrado em Educação - Linha de pesquisa: Educação e Linguagem). Centro de Educação, Universidade Federal de Pernambuco. Recife, 2014.

ÁVILA, Ewerton; NASCIMENTO, Gláucia; GOIS, Siane. Ensino de oralidade: revisitando os documentos oficiais e conversando com professores. In: LEAL, Telma Ferraz; GOIS, Siane (Orgs.). A oralidade na escola: a investigação do trabalho docente como foco de reflexão. Belo Horizonte: Autêntica Editora, 2012, p. 37-56 (Coleção Língua Portuguesa na Escola, 3).

BRONCKART, Jean-Paul. Atividade de linguagem, textos e discursos: por um interacionismo sócio-discursivo. São Paulo: EDUC, 2003.

DOLZ, Joaquim; NOVERRAZ, Michèle; SCHNEUWLY, Bernard. Sequências didáticas para o oral e a escrita: apresentação de um procedimento. In: ROJO, Roxane; CORDEIRO, Glaís Sales (Orgs.). Gêneros orais e escritos na escola. Campinas: Mercado de Letras, 2004, p. 81-108 (Coleção As Faces da Linguística Aplicada). 
DOLZ, Joaquim; SCHNEUWLY, Bernard; HALLER, Sylvie. O oral como texto: Como construir um objeto de ensino. In: ROJO, Roxane; CORDEIRO, Glaís Sales (Orgs.). Gêneros orais e escritos na escola. Campinas: Mercado de Letras, 2004, p. 125-155 (Coleção As Faces da Linguística Aplicada).

LIMA, Ana; BESERRA, Normanda. Sala de aula: espaço também da fala. In: LEAL, Telma Ferraz; GOIS, Siane (Orgs.). A oralidade na escola: a investigação do trabalho docente como foco de reflexão. Belo Horizonte: Autêntica Editora, 2012, p. 57-72 (Coleção Língua Portuguesa na Escola, 3).

MARCUSCHI, Luiz Antônio; DIONÍSIO, Ângela Paiva. Princípios Critérios para a avaliação da oralidade no ensino de língua portuguesa gerais para o tratamento das relações entre a fala e a escrita. In: Fala e escrita. $1^{\mathrm{a}}$ ed., $1^{\mathrm{a}}$ reimp. Belo Horizonte: Autêntica, 2007, p. 13-30.

MELO, Cristina Teixeira Vieira de; CAVALCANTE, Marianne Carvalho Bezerra. Superando os obstáculos de avaliar a oralidade. In: MARCUSCHI, Beth; SUASSUNA, Lívia (Orgs.). Avaliação em língua portuguesa: contribuições para a prática pedagógica. $1^{\mathrm{a}} \mathrm{ed}, 1^{\mathrm{a}}$ reimp. Belo Horizonte: Autêntica, 2007, p. 75-93.

MELO, Cristina Teixeira Vieira de; MARCUSCHI, Beth; CAVALCANTE, Marianne Carvalho Bezerra. Esclarecendo o trabalho com a oralidade: uma proposta didática. In: LEAL, Telma Ferraz; GOIS, Siane (Orgs.). A oralidade na escola: a investigação do trabalho docente como foco de reflexão. Belo Horizonte: Autêntica Editora, 2012, p. 95-114 (Coleção Língua Portuguesa na Escola, 3).

MILANEZ, Wania. Pedagogia do oral: a elocução formal sob o prisma textual-interativo. 207f. Tese (Doutorado em Ciências - Linguística). Instituto de Estudos da Linguagem, Universidade Estadual de Campinas. Campinas, 1992.

Pedagogia do oral: condições e perspectivas para sua aplicação no português. Campinas: Sama, 1993. 
SCHNEUWLY, Bernard. Palavra e ficcionalização: um caminho para o ensino da linguagem oral. In: ROJO, Roxane; CORDEIRO, Glaís Sales (Orgs.). Gêneros orais e escritos na escola. Campinas: Mercado de Letras, 2004b, p. 109-124 (Coleção As Faces da Linguística Aplicada).

SCHNEUWLY, Bernard; DOLZ, Joaquim. Os gêneros escolares: Das

Flávia Santana

Araújo

Lívia

Suassuna práticas de linguagem aos objetos de ensino. In: ROJO, Roxane; CORDEIRO, Glaís Sales (Orgs.). Gêneros orais e escritos na escola. Campinas: Mercado de Letras, 2004, p. 61-78 (Coleção As Faces da Linguística Aplicada). 